\title{
Incentive and Supervisory Contract between Special Committees and CEO Based on the Evolutionary Game Model
}

\author{
Chuanbo Zhang $\mathbb{D}^{1},{ }^{1}$ Kangkang Lin $\mathbb{D}^{2},{ }^{2}$ and Lei Wang $\mathbb{D}^{3}$ \\ ${ }^{1}$ College of Energy and Mining Engineering, Shandong University of Science and Technology, Qingdao 266590, China \\ ${ }^{2}$ College of Economics and Management, Shandong University of Science and Technology, Qingdao 266590, China \\ ${ }^{3}$ School of Economics, Ocean University of China, Qingdao 266100, China
}

Correspondence should be addressed to Kangkang Lin; lin_kangkang_k@163.com

Received 17 December 2019; Revised 6 June 2020; Accepted 20 June 2020; Published 16 October 2020

Academic Editor: Ezequiel López-Rubio

Copyright (c) 2020 Chuanbo Zhang et al. This is an open access article distributed under the Creative Commons Attribution License, which permits unrestricted use, distribution, and reproduction in any medium, provided the original work is properly cited.

\begin{abstract}
The process of CEO incentive and supervision, in which the special committee plays an important role, has always been a hard problem to solve in modern corporate governance. Considering the conflicts of interest between the compensation committee, audit committee, and the CEO, this paper constructed a game model of incentive and supervision within the board of directors and analysed the strategic choices of all three and the influencing mechanisms in different contexts. The results show that there is no totally stable strategy point in the system and that there are different strategy choices in different situations; the CEO's strategy choice is influenced by both the compensation committee and the audit committee, the incentive strategy of the compensation committee will promote the CEO's self-interested behaviour, and the supervision strategy of the audit committee is inhibitive. The function of the special committee is dependent on its initial intention and the intensity of action. In the situation of excessive incentive by the compensation committee, the strategy choice of audit committee has periodicity, and the CEO and audit committee have periodic discretionary choice game. This study provides insight into the internal governance of the board of directors, particularly special committees, which create the incentive and supervisory contracts.
\end{abstract}

\section{Introduction}

In 2018, the China Securities Regulatory Commission revised and officially issued the Code of Corporate Governance for Listed Companies, in which it was stipulated that the board of directors of a listed company should establish special committees in accordance with the resolutions of shareholder meetings. Special committees are accountable to the board of directors and perform their duties based on the company's articles of association and the authorisation of the board of directors. In particular, special committees should play an active role in governance to incentivise and supervise the CEO. Kalelkar [1], Collier and Gregory [2], Sultana et al. [3], and Bajra and Čadež [4] discovered that the supervision efforts of the audit committee can improve the quality of a company's financial reports and reduce financial risks. Ghafran and O'Sullivan [5] noted that an audit committee with a professional background can inhibit an agent's earnings manipulation behaviour.

However, the governance effect of the special committee has also been questioned. U. Hoitash and R. Hoitash [6] pointed out that a board of directors is an elite group which faces many tasks. Therefore, a board of directors often delegates different board functions to different special committees. However, it is difficult to reach an optimal decision, as the varying goals of each group can lead to conflicts of interest. In addition, there is a free-riding problem between directors regarding the issue of supervising managers. For example, in order to encourage executive agents to provide greater economic output, the compensation committee will set a higher incentive coefficient $[7,8]$. In fact, compensation committee existence and effectiveness are positively associated with CEO pay-performance alignment [9]. Accordingly, it requires the audit committee 
to pay greater supervision costs, which increases supervision costs and weakens the effectiveness of the compensation committee in motivating the CEO [10]. The inconsistency between the principal and the agent intensifies the difficulty of governance. Therefore, it has become important in solving corporate governance problems to design an effective compensation contract which achieves the coordination of the interests of both parties [11].

The administration of the board of directors is directly related to the survival and development of listed companies. Figure 1 shows the structure of corporate governance for listed companies in China. The board of directors of a listed company must establish a corporate strategy committee, an audit committee, a nomination committee, a compensation committee, and other special committees in accordance with the resolutions of shareholder meetings. All committees must be composed solely of directors. In the United States, almost all companies have established three key committees: audit committee, compensation committee, and nomination/corporate governance committee. Most directors of these committees are external directors. In China, corporate governance is at the stage of deepening reform, and we attempted to explore the strategic choice of incentive and supervision of special committees from the aspect of internal corporate governance and further study whether the special committee can effectively play a role in Chinese corporate governance. These two reasons provided motivation for our research.

Therefore, this paper focuses on the issue of executive incentive and supervision and uses the CEO, compensation committee, and audit committee as basic behaviour decision-makers in order to construct a three-party evolutionary game model. Furthermore, considering the characteristics of self-interested behaviour of CEOs, this paper studies the strategic choice of incentive and supervision of special committees, analyses the influence of different evolutionary behaviour on decision-making under the participation of multiagents, attempts to expand the existing research ideas of principal-agent theory, and constructs the internal framework of corporate governance from the perspective of special committees. We discover that there is no stable equilibrium point in the system, and one of the strategic choices is influenced by the other two parties. Due to the presence of the free-rider problem, there may be excessive incentives in the compensation committee. However, if the audit committee adopts active governance, the $\mathrm{CEO}$ and audit committee both have periodic discretionary choice. From the perspective of governance effect, the CEO's strategy choice is influenced by the special committees and passively undertakes the incentive and supervision.

The innovations of this paper are mainly focused on the following two aspects. Firstly, we introduce the special committees under the framework of managerial power theory. Evolutionary game method is applied in order to explain the CEO's contract formulation from a dynamic perspective, and the linkage between the CEO and special committees and the long-term evolution of the three are analysed. Secondly, this paper explains the influence path of initial decision-making willingness and the level of action effort of participating parties on their stability strategies. We examine the effect of CEO self-interested behaviour, the incentive coefficient of the compensation committee, and the supervision intensity of the audit committee on the choice of the three parties' strategies. We also explain the strategic choices of participating entities in different situations, which may reveal more about special committees' participation in CEO incentive and supervision.

This paper is organized as follows. Section 2 provides a literature review. Section 3 establishes a tripartite evolutionary game model of incentive and supervision and puts forward a payoff matrix of the CEO and specials committee under different scenarios. Section 4 lists the replicated dynamic equations of the $\mathrm{CEO}$, compensation committee, and audit committee and explores the evolutionary stable strategies by solving the asymptotic stability of the equilibrium points. The results of numerical simulation of the ultimate evolutionary stable strategies and of their relevant parameters, together with empirical analysis, are presented in Section 5. Finally, Section 6 discusses the conclusions and implications.

\section{Literature Review}

Principal-agent theory is the earliest theoretical basis for the study of managerial incentives, and it explains how to design the incentive mechanism between participating entities under asymmetric information conditions and then realises the coordination of the interests of stakeholders. Furthermore, the optimal contract theory derived from this foundation believes that the board of directors can reduce the agency costs for both agents by designing effective incentive mechanisms. For example, Yu et al. [12] note that shareholders can sign optimal incentive contracts with managers in order to achieve a coordination of interests and ease the self-interested behaviour of executive agents. Jensen and Meckling [13] believe that the introduction of stock options can link the interests of shareholders and executives which can reduce agency costs. Furthermore, while an agent pursues explicit incentives such as salary, implicit incentives such as reputation also play important roles, and they can be used as an alternative mechanism for explicit incentives to avoid moral hazard [14, 15]. Schrader and Sun [16], Alvi [17], and Markus et al. [18] further studied the influence of executives' bounded rationality behaviour on the optimal incentive contract, introduced fairness preference and self-interested behaviour of senior executives into the principal-agent model, and extended research on the incentive theory of executive agents.

However, the premise of the application of optimal contract theory is that the board of directors and executives are completely independent of each other [19]. The board of directors can fully exert checks and balances on the executives. In real life, executives can control the board by using the power they possess. For example, executive agents use their prestige to intervene in board decisions or collude with board members in order to curtail performance for selfinterested behaviour, which affects the development of the board's compensation contract. The managerial power theory proposed by Bebchuk et al. [20] poses a great challenge to traditional contract theory. It is believed that the 


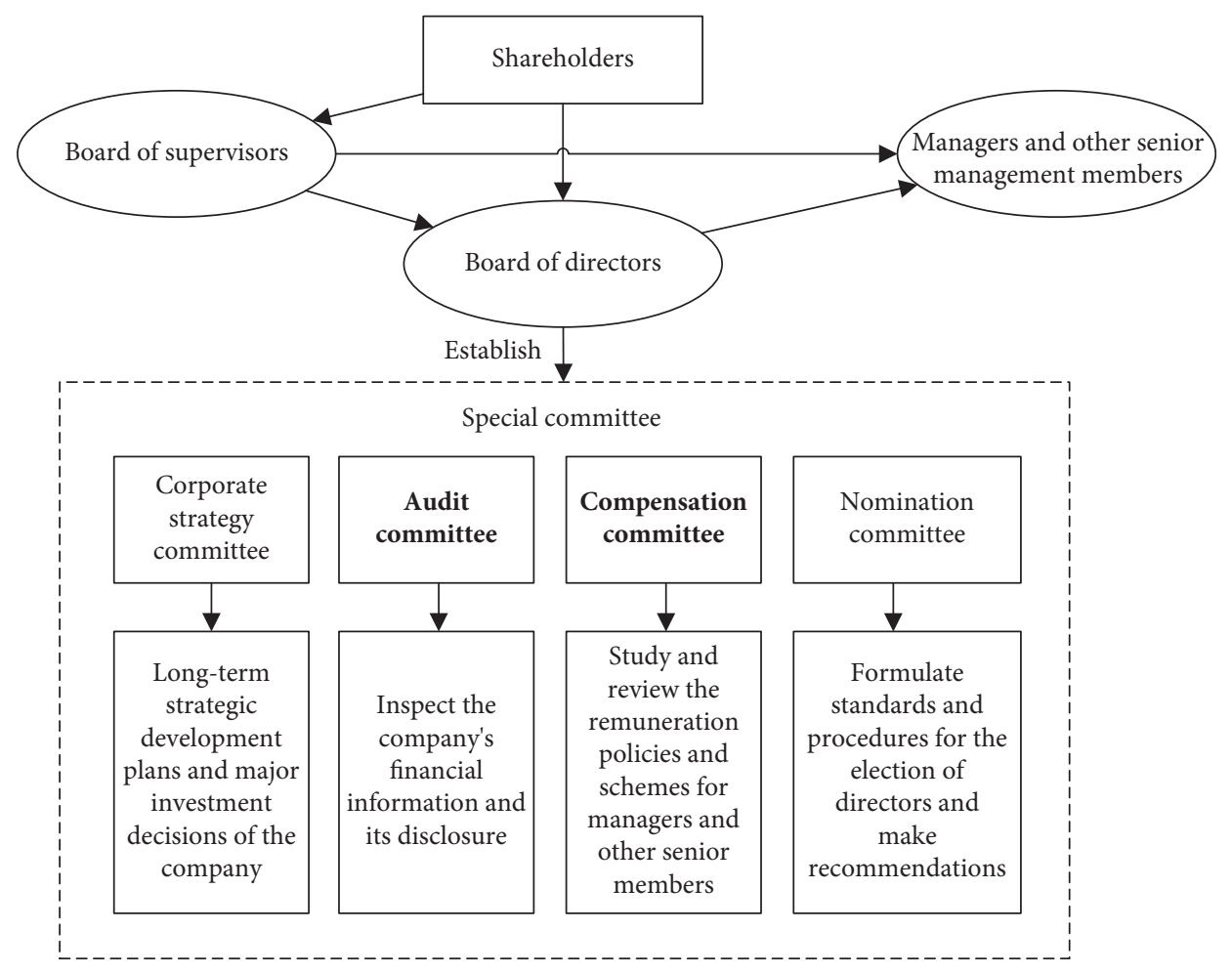

FIgURE 1: Structure of corporate governance for listed companies in China.

incentive contract of executive agencies not only can solve the agency problem but also is itself the product of the agency problem [21]. Particularly in the context of China's state-owned enterprises with serious owner absence and internal control, managers must exercise strong discretion with corporate decision-making. In the absence of clear owner supervision, state-owned executives are more likely to use their power to seek personal gain [22]. Therefore, when designing a reasonable salary incentive mechanism under the framework of managerial power theory, effective supervision is also necessary $[23,24]$. The method of realising the incentive and supervision functions of special committee members constitutes the research motivation for this paper.

It can be seen from the above literature that research on the incentives of executive agents is mostly focused on principal-agent theory, optimal contract theory, and managerial power theory [25] and studies the three-tier agency relationship of shareholder-director-executive management in the principal-agent relationship. This neglects the heterogeneous behavioural decisions of the special committees which divide different subjects based on their different responsibilities. Previous research has mostly analysed the effectiveness of special committees' participation in governance from a static perspective. In reality, the strategy choice of the subject is influenced by other participants, and this is a dynamic evolutionary process.

\section{Incentive and Supervision Model}

In order to further analyse the issue of incentive and supervision in special committees with different responsibilities, we selected the CEO, compensation committee, and audit committee as the participants. The CEO represents the executive agent and may adopt optimal strategy to ensure that his choice is the best, including normal productive activities and self-interested behaviour. The compensation committee is responsible for formulating CEO compensation and deciding whether to conduct incentives and incentive factors. The audit committee oversees financial statements and decides whether supervision is necessary [15]. For example, in order to reduce CEO self-interested behaviour and weaken agent earnings management, the compensation committee can choose to reduce the incentive coefficient and the audit committee can increase the intensity of supervision over financial reports. This will weaken not only the CEO's selfinterested behaviour but also their normal productive activities. Therefore, this article establishes a multievolutionary game model. Given the different combinations of strategies of the CEO, compensation committee, and audit committee, this paper analyses their governance choices and optimal evolution paths in order to explore the stable equilibrium points of multiagent games.

The audit committee plays a key role in inspecting the company's financial information and its disclosure. Due to information asymmetry, the CEO has the information advantage to control the enterprise and will provide information to the audit committee based on the maximisation of interests. Also, the CEO is unwilling to reveal information which helps directors provide advice, as directors can also use the information for monitoring purposes. Therefore, the information provided may not be enough to supervise the $\mathrm{CEO}$ and improve the quality of financial reports. When 
designing the compensation scheme for the CEO, the compensation committee may provide strong incentives to the CEO, which will lead to a performance measure which is manipulable through earnings management by the CEO. Therefore, the audit committee is under greater pressure to diligently perform the oversight task.

In practice, the audit committee can increase the effort devoted to overseeing the financial reporting process. For example, the audit committee may invest more time and energy into collecting financial information and providing critical oversight of the company's financial reporting and auditing processes. The monitoring effort $e$ captures the time and attention the audit committee devotes to its duties such as arranging meetings with management to discuss annual and quarterly financial statements, engaging in vigorous debate, and asking probing questions. It is also possible to hire independent external auditors to verify service delivery and quality, and this increases costs.

3.1. Hypothesis of the Evolutionary Game Model. Based on evolutionary game model construction theory and the above analysis, this paper makes the following assumptions:

(i) Shareholders do not participate in direct governance. They will not only entrust the CEO to engage in management and decision-making but also entrust the board of directors to conduct internal governance. More specifically, shareholders ordinarily determine different special committees for engaging in incentive and supervision, including the compensation committee and the audit committee [10].

(ii) In the principal-agent game system, all three parties have the power and scheme of their respective behaviour choices. Each participant has two options: the CEO may adopt the strategy of self-interested behaviour and may also choose not to implement self-interested behaviour, which is hereafter referred to as "self-interested" or "not selfinterested." Correspondingly, the compensation committee has the strategy set "incentive" or "not incentive," and the audit committee has the strategy set "supervise" or "not supervise."

(iii) Without considering other constraints, the special committees and the CEO constitute a complete system. All three parties are limited rational individuals with the ability to learn. That is to say, the three parties in the game are constantly seeking to adjust their own strategic choices during the process of learning and imitation, in order to find the best combination of strategies until equilibrium is reached [26].

(iv) We used evolutionary game method to construct the strategic choices of the CEO, compensation committee, and audit committee and assumed all to be independent individuals, with bounded rationality, who would adopt a strategy in order to maximise their own interests. (v) We define the audit committee's cost as $c(e)=0.5 e^{2}$, which is increasing and strictly convex. The supervision effort $e$ captures the time and attention the audit committee devotes to its duties such as arranging meetings with management to discuss annual and quarterly financial statements, engaging in vigorous debate, and asking probing questions.

3.2. Parameters. The parameter and variable symbols and their meanings are shown in Table 1. Based on the evolutionary game model construction theory and the above analysis, this paper makes the following assumptions.

3.2.1. CEO Payoffs. The CEO may choose to engage in productive activity $a_{1}$ or self-interested behaviour $a_{2}$. Normal productive activity will bring greater revenue performance and cash flow to the company, while self-interested behaviour can provide private benefits for the CEO but will have a negative impact on cash flow. For example, it may stem from distortions in company operations and investment decisions, as well as potential litigation costs and reputational losses.

The total salary the CEO receives is $w(M)=F+b M$ and consists of a fixed component $F$ and a variable component $b M$. We define the cost paid by the CEO during his tenure as a quadratic function of the effort behaviour, $c(\alpha)=0.5 \alpha_{1}^{2}+$ $0.5 \alpha_{2}^{2}$, reflected in the fact that productive behaviour sacrifices leisure time to cause utility loss, and self-interested behaviour must bear the cost from litigation, reputation, or spiritual loss. We also use $U_{\mathrm{CEO}}$ to measure the CEO's utility, including the positive effects of compensation and the negative effects of the effort cost of the activity:

$$
U_{\mathrm{CEO}}=F+b\left[m_{1} a_{1}+m_{2}(1-e) a_{2}\right]-c(a) .
$$

When the CEO chooses not to engage in self-interested behaviour, we obtain $a_{2}=0$.

3.2.2. Compensation Committee Payoffs. As an indicator of the economic output of CEO effort, we define $m_{i}$ as the sensitivity coefficient of performance to $\mathrm{CEO}$ behaviour. In particular, $m_{1}$ indicates the sensitivity of performance to productive activities, while $m_{2}$ represents the sensitivity of performance to CEO self-interested behaviour. In addition, we assume that performance is more sensitive to productive activities than to self-interested behaviour, that is $m_{1}>m_{2}$. The performance measure is therefore given by $M=m_{1} a_{1}+$ $m_{2} a_{2}$. The compensation committee may set an incentive coefficient $b$ for measuring the contribution of CEO behaviour to performance.

The CEO's efforts will provide final gross cash flow $Y$ to the company. We define a function embodied in the CEO's effort and the expression is given by $Y=v_{1} a_{1}-v_{2} a_{2}$. In addition, $v_{1}$ represents the sensitivity of final gross cash flow to productive activities, while $v_{2}$ represents the sensitive coefficient of final gross cash flow to self-interested behaviour, also satisfying $v_{1}>v_{2}$. The ultimate goal of 
TABle 1: Parameters and variables symbol descriptions.

\begin{tabular}{lc}
\hline Parameters & Descriptions \\
\hline$a_{1}$ & Productive activity of CEO \\
$a_{2}$ & Self-interested behaviour of CEO \\
$w(M)$ & Total salary paid to CEO \\
$F$ & Fixed component of total salary \\
$c(a)$ & CEO's cost \\
$U_{\text {CEO }}$ & CEO's utility \\
$m_{1}$ & Sensitivity of performance to productive activities \\
$m_{2}$ & Sensitivity of performance to CEO self-interested behaviour \\
$M$ & Firm's performance \\
$Y$ & Final gross cash flow \\
$v_{1}$ & Sensitive coefficient of final gross cash flow to self-interested behaviour \\
$v_{2}$ & Net value of the firm \\
$V$ & A fixed salary paid to audit committee \\
$w_{0}$ & Correlation coefficient between the special committees which link their utility with the net value of the firm \\
$\beta$ & An incentive coefficient adopted by compensation committee \\
$b$ & Compensation committee's utility \\
$U_{\text {comp }}$ & The supervision of the audit committee \\
$e$ & Audit committee's cost \\
$c(e)$ & Audit committee's utility \\
$U_{\text {audit }}$ & The probability that compensation committee adopts incentive strategy \\
$x$ & The probability that audit committee adopts supervisory strategy \\
$y$ &
\end{tabular}

shareholders is to maximise the net value of the company $V=Y-w(M)-w_{0}$. As shareholder spokesperson, the special committees link their utility to the net value of the firm, and we define the correlation coefficient as $\beta$, and the compensation committee's utility is therefore given by

$$
\begin{aligned}
U_{\mathrm{comp}}= & \beta\left[v_{1} a_{1}-v_{2}(1-e) a_{2}-F\right. \\
& \left.-b\left(m_{1} a_{1}+m_{2}(1-e) a_{2}\right)-w_{0}\right] .
\end{aligned}
$$

When the compensation committee does not take incentive, we obtain $b=0$.

3.2.3. Audit Committee Payoffs. We define the supervision of the audit committee as $e$, which has two aspects. On one hand, it will reduce CEO's self-interested behaviour, and therefore the sensitivity of performance to the self-interested activities is given by $m(e)=m_{2}(1-e)$. On the other hand, it can weaken the violation of the CEO's self-interested behaviour on the final cash flow of firm, so the sensitivity coefficient of the cash flow of the company to the self-interested behaviour of the $\mathrm{CEO}$ is given as $v(e)=v_{2}(1-e)$. At the same time, we define $w_{0}$ as the fixed salary which is paid to the audit committee and can motivate the audit committee to provide effective supervision over the CEO, and the cost of supervision by the audit committee is given as $c(e)=0.5 e^{2}$. We obtain the audit committee's utility as follows:

$$
\begin{aligned}
U_{\text {audit }}= & \beta\left[v_{1} a_{1}-v_{2}(1-e) a_{2}-F\right. \\
& \left.-b\left(m_{1} a_{1}+m_{2}(1-e) a_{2}\right)-w_{0}\right]+w_{0}-0.5 e^{2} .
\end{aligned}
$$

When the audit committee does not supervise, it satisfies $e=0$.
In formula (3), we assume that the supervision of the audit committee (e) can reduce the CEO's self-interested behaviour and/or weaken the effect of the CEO's self-interested behaviour on cash flow reduction.

The performance measure is therefore given by $M=m_{1} a_{1}+m_{2}(1-e) a_{2}$; the productive activity $a_{1}$ positively affects both the performance measure and the final cash flow of the firm. In contrast, the self-interested behaviour only increases the performance measure, possibly at the expense of long-term gross cash flow. At the same time, the audit committee chooses the supervision intensity, $e$. Diligent supervision by the audit committee makes it more difficult for the CEO to successfully manipulate the performance measure.

The CEO's efforts will provide the final gross cash flow $Y$ to the company. We define a function embodied in the CEO's effort and the expression is given by $Y=v_{1} a_{1}-v_{2}(1-e) a_{2}$. The negative effect of $a_{2}$ on cash flow may stem from distortions of the firm's operating and investment decisions, as well as the cost of potential litigation and loss of reputation. We know that the self-interested behaviour of CEO $a_{2}$ is detrimental to shareholders, as it can lead to excessive CEO compensation. Also, the supervision intensity, $e$, can weaken the negative effect by inspecting the company's financial information and its disclosure.

3.3. Construction of Payoff Matrix. Based on the above hypothesis and the use of the three-party payoff variable, the three-party evolutionary game payoff matrix of the CEO, compensation committee, and audit committee is constructed, as demonstrated in Table 2. 


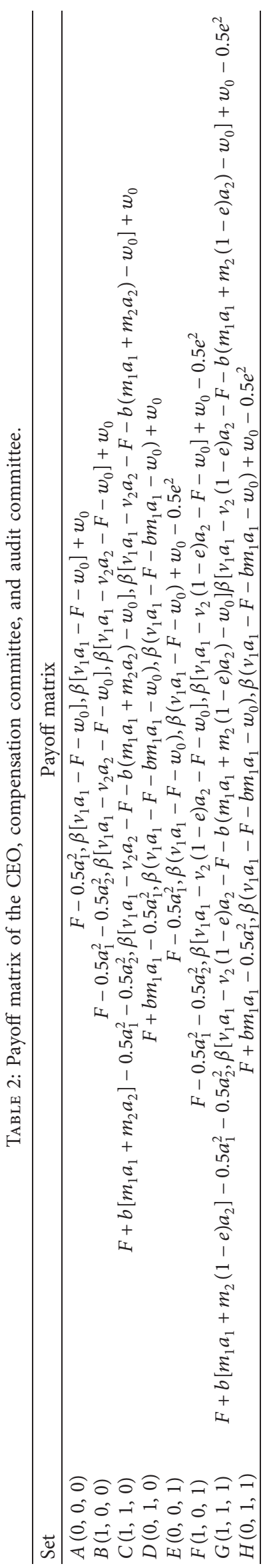




\section{Systematic Stability Analysis}

4.1. Expected Function Construction. At the primary stage, we assume that the self-interested CEO accounts for $x$, while the not self-interested CEO accounts for $1-x$. Similarly, the incentive compensation committee accounts for $y$ and the not incentive compensation committee accounts for $1-y$. The supervise audit committee accounts for $z$ and the not supervise audit committee accounts for $1-z$. It satisfies $0 \leq x, y, z \leq 1$.

4.1.1. CEO's Expected Utility. The respective expectation values of self-interested and not self-interested behaviour are $U_{\mathrm{CEO}}(1)$ and $U_{\mathrm{CEO}}(0)$; then,

$$
\begin{aligned}
U_{\mathrm{CEO}}(1)= & F+y b\left[m_{1} a_{1}+m_{2}(1-e) a_{2}\right] \\
& -0.5 \alpha_{1}^{2}-0.5 \alpha_{2}^{2}+(1-z) y b e m_{2} a_{2}, \\
U_{\mathrm{CEO}}(0)= & F+y b m_{1} a_{1}-0.5 \alpha_{1}^{2} .
\end{aligned}
$$

4.1.2. Compensation Committee's Expected Utility. The respective expectation values of incentive and not incentive are $U_{\text {comp }}(1)$ and $U_{\text {comp }}(0)$; then,

$$
\begin{aligned}
& U_{\text {comp }}(1)=\beta\left[v_{1} a_{1}-F-b m_{1} a_{1}-w_{0}-x(1-z e)\left(v_{2}+b m_{2}\right)\right], \\
& U_{\text {comp }}(0)=\beta\left[v_{1} a_{1}-F-w_{0}-x(1-z) e v_{2} a_{2}\right] .
\end{aligned}
$$

4.1.3. Audit Committee's Expected Utility. The respective expectation values of supervise and not supervise are $U_{\text {audit }}(1)$ and $U_{\text {audit }}(0)$; then,

$$
\begin{aligned}
U_{\text {audit }}(1)= & \beta\left[v_{1} a_{1}-F-w_{0}-y b m_{1} a_{1}\right. \\
& \left.-x y b m_{2}(1-e) a_{2}-x v_{2}(1-e) a_{2}\right]+w_{0}-0.5 e^{2}, \\
U_{\text {audit }}(0)= & \beta\left[v_{1} a_{1}-x v_{2} a_{2}-F-y b m_{1} a_{1}\right. \\
& \left.-x y b m_{2} a_{2}-w_{0}\right]+w_{0} .
\end{aligned}
$$

4.2. Replicator Dynamics Analysis. According to the principle of the stability theorem of the replication dynamic differential equation and evolutionary stability strategy, when $F(x)=0$ and $F^{\prime}(x)<0$ are satisfied, this meaning that all games are stable, and $x$ is a stability strategy point of the evolution game.

4.2.1. Replicator Dynamics Analysis of the Self-Interested CEO. The CEO's strategic choice is influenced by two special committees. Considering the payoff function of choosing self-interested behaviour, the replicator dynamics formula of the self-interested CEO is

$$
\begin{aligned}
F(x) & =\frac{\mathrm{d} x}{\mathrm{~d} t}=x(1-x)\left[U_{\mathrm{CEO}}(1)-U_{\mathrm{CEO}}(0)\right] \\
& =x(1-x)\left[y b m_{2}(1-z e) a_{2}-0.5 a_{2}^{2}\right], \\
F^{\prime}(x) & =\frac{\mathrm{d} F(x)}{\mathrm{d} x}=(1-2 x)\left[y b m_{2}(1-z e) a_{2}-0.5 a_{2}^{2}\right] .
\end{aligned}
$$

Let $F(x)=0$; then, games are stable when $x=0, x=$ $1, y^{*}=\left(a_{2} /\left(2 b m_{2}(1-z e)\right)\right)$ :

(i) When $y=y^{*}$ is satisfied, then $F(x)=0$ and $F^{\prime}(x)=0$, meaning that all games are stable. It can be observed that when the CEO can obtain the behaviour information of the special committee, self-interested behaviour is the best strategy choice for the CEO. Particularly, when the condition $a_{2}=2 b m_{2}(1-z e) y$ is satisfied, the special committees have no influence at all on the CEO's behaviour choice. This also explains from another aspect that when the CEO adopts certain selfinterested behaviour, the special committees cannot play an effective incentive and supervision role.

(ii) If $y>y^{*}$ and $x=1$ are satisfied; then $F(x)=0$ and $F^{\prime}(x)<0$. Therefore, $x=1$ is the equilibrium point. When the CEO's self-interested behaviour reaches $a_{2}=2 b m_{2}(1-z e) y$ and shows an increasing trend, the CEO may adopt self-interested behaviour as their optimal strategy choice in order to maximise their private interests. At this time, the CEO is more willing to become selfinterested.

(iii) If $y<y^{*}$ and $x=0$ are satisfied, then $F(x)=0$ and $F^{\prime}(x)<0$. Therefore, $x=0$ is the equilibrium point. Similarly, when the CEO's self-interested behaviour reaches $a_{2}=2 b m_{2}(1-z e) y$ and shows a decreasing trend, it is the best strategy choice for the CEO not to choose self-interested behaviour. It is more favourable to be a qualified CEO in order to improve the utility level.

From the above analysis, we can obtain the dynamic tendency and stability of the CEO, which is shown in Figure 2.

4.2.2. Replicator Dynamics Analysis of the Incentive Compensation Committee. The compensation committee is mostly responsible for stimulating the CEO to engage in productive activities. Based on the CEO's efforts and the audit committee's supervisory strength, the compensation committee determines whether to adopt an incentive strategy and incentive intensity. Therefore, the compensation committee adopts the incentive dynamic replication dynamic equation as 


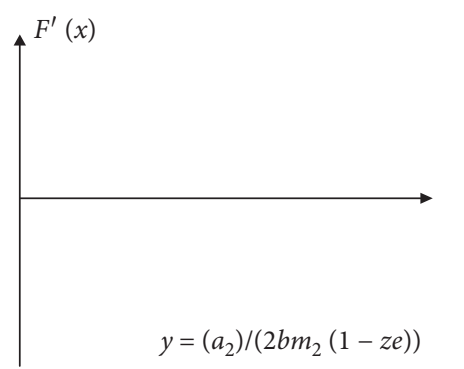

(a)

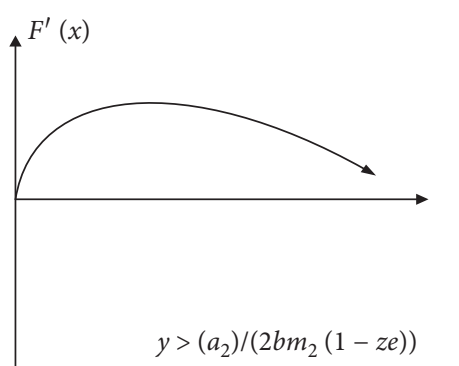

(b)

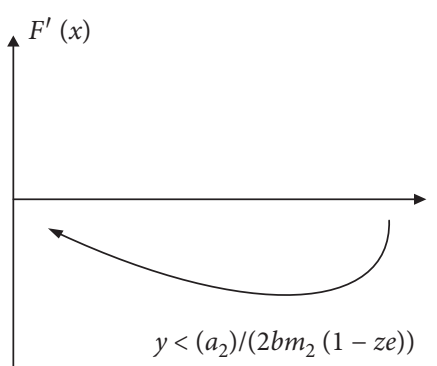

(c)

Figure 2: CEO's replicator dynamics phase charts.

$$
\begin{aligned}
F(y)= & \frac{\mathrm{d} y}{\mathrm{~d} t}=y(1-y)\left[U_{\text {comp }}(1)-U_{\text {comp }}(0)\right] \\
= & y(1-y) \beta\left[-b m_{1} a_{1}+x(e-1) v_{2} a_{2}-x(1-z e) b m_{2} a_{2}\right] \\
F^{\prime}(y)= & \frac{\mathrm{d} F(y)}{\mathrm{d} y}=(1-2 y) \beta\left[-b m_{1} a_{1}\right. \\
& \left.+x(e-1) v_{2} a_{2}-x(1-z e) b m_{2} a_{2}\right]
\end{aligned}
$$

Let $F(y)=0$; then, games are stable when $z^{*}=\left(\left(b m_{1} a_{1}+x(1-e) v_{2} a_{2}+x b m_{2} a_{2}\right) /\left(x b e m_{2} a_{2}\right)\right)$, $y=0$, and $y=1$ :

(i) When $z=z^{*}$ is satisfied, then $F(y)=0$ and $F^{\prime}(x)=0$. This means that evolutionary stable strategies are achieved. It can be seen that when the probability of the supervisory behaviour of the special committee meets the above conditions, the behaviour choice of the compensation committee has no effect on the CEO or the audit committee.

(ii) If $z>z^{*}$ and $y=1$ are satisfied, then $F(y)=0$ and $F^{\prime}(y)<0$. Therefore, $y=1$ is the equilibrium point. When the compensation committee can confirm that the audit committee has a high probability of supervision and shows an increasing trend, then the compensation committee will adopt the incentive strategy as its optimal strategy choice. Due to the strong supervision of the audit committee, it is able to impose certain constraints on the self-interested behaviour of the CEO. The compensation committee achieves the purpose of stimulating the CEO's hard work by formulating an incentive plan, thereby maximising the interests of shareholders.

(iii) If $z<z^{*}$ and $y=0$ are satisfied, then $F(y)=0$ and $F^{\prime}(y)<0$. Therefore, $y=0$ is the equilibrium point. When the compensation committee has sufficient information to determine that the supervision strength of the audit committee has a lower level of supervision, the optimal decision of the compensation committee is to not adopt the incentive. As the information which the audit committee does not supervise is also captured by the CEO, in order to curb the excessive self-interested behaviour of the CEO, the compensation committee may choose not to set a high incentive.
From the above analysis, we can obtain the dynamic tendency and stability of the compensation committee, which is shown in Figure 3.

4.2.3. Replicator Dynamics Analysis of the Supervise Audit Committee. The audit committee must consider the strategies of the CEO and the compensation committee when formulating its own strategy, in order to determine the intensity of supervision under the premise of maximising self-interest. Therefore, the audit committee selects the replication dynamic equation of the supervision strategy as

$$
\begin{aligned}
& F(z)=\frac{\mathrm{d} z}{\mathrm{~d} t}=z(1-z)\left\{\beta\left[x v_{2} e a_{2}+x y b e m_{2} a_{2}\right]-0.5 e^{2}\right\} \\
& F(z)=\frac{\mathrm{d} F(z)}{\mathrm{d} z}=(1-2 z)\left\{\beta\left[x v_{2} e a_{2}+x y b e m_{2} a_{2}\right]-0.5 e^{2}\right\} .
\end{aligned}
$$

Let $F(z)=0$; then games are stable when $x^{*}=$ $\left(0.5 e^{2} /\left(\beta\left(v_{2} e a_{2}+y b e m_{2} a_{2}\right)\right)\right), z=0$ and $z=1$ :

(i) When $x=x^{*}$ is satisfied, then $F(z)=0$ and $F^{\prime}(z)=0$. It can be seen that when the audit committee obtains the probability information that the CEO chooses self-interested behaviour to meet the above conditions, whether the supervision strategy is adopted or not is its optimal strategy choice. At this time, all three parties achieve a shortterm Nash equilibrium, where the CEO chooses self-interested behaviour, and the audit committee does not supervise, resulting in a situation which is similar to the prisoner's dilemma.

(ii) If $x>x^{*}$ and $z=1$ are satisfied, then $F(z)=0$ and $F^{\prime}(z)<0$. Therefore, $y=1$ is the equilibrium point. If the audit committee has sufficient confidence to confirm that the CEO will adopt self-interested behaviour, then the optimal strategy is to supervise, thereby avoiding the occurrence of the CEO's selfinterested behaviour affecting the interests of shareholders.

(iii) If $x<x^{*}$ and $z=0$ are satisfied, then $F(z)=0$ and $F^{\prime}(z)<0$. Therefore, $z=0$ is the equilibrium point. When the audit committee does not have sufficient information to confirm that the CEO will conduct 


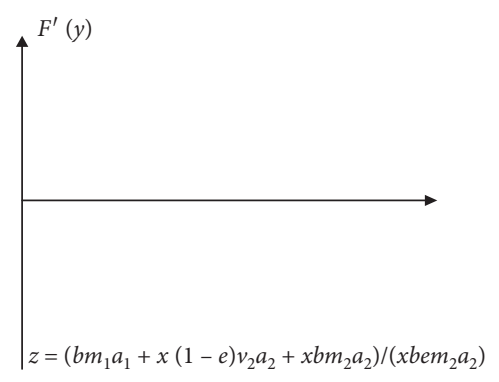

(a)

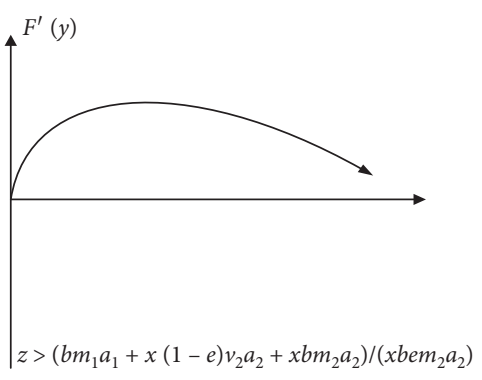

(b)

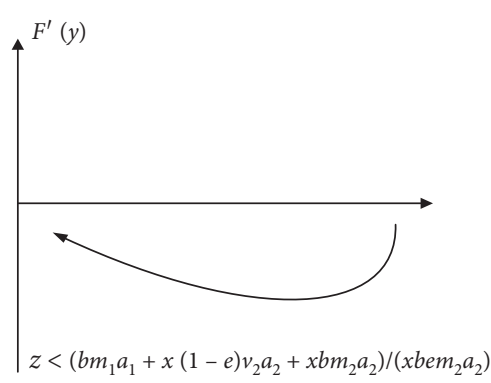

(c)

FIgURE 3: Compensation committee's replicator dynamics phase charts.

self-interested behaviour or that previous experience shows that the probability of the CEO choosing selfinterested behaviour is small; then in order to avoid unnecessary costs, the audit committee will choose not to supervise as its optimal strategy choice.

From the above analysis, we can obtain the dynamic tendency and stability of the audit committee, which is shown in Figure 4.

4.3. Systematic Stability Analysis. The evolution of the threeparty group of CEO, compensation committee, and audit committee can be expressed using the three differential equations above, but it is difficult to directly judge the stability of the final evolutionary equilibrium point due to the dynamic changes of the system. According to the concept of evolutionary equilibrium points which is proposed by Hirshleifer, when the trajectory starting from any small field of a dynamic equilibrium point eventually evolves towards the equilibrium point, the equilibrium point is then referred to as the evolution equilibrium point. Combined with the decision method proposed by Friedman [26], when the Jacobian matrix $J$ is satisfied, $\operatorname{det} J>0, \operatorname{tr} J<0$, the equilibrium point is the evolutionarily stable strategy (ESS). Therefore, according to the above strategy, the Jacobian matrix is constructed to analyse the stability of the equilibrium solution:

$$
\begin{aligned}
J= & {\left[\begin{array}{lll}
\frac{\partial F(x)}{\partial x} & \frac{\partial F(x)}{\partial y} & \frac{\partial F(x)}{\partial z} \\
\frac{\partial F(y)}{\partial x} & \frac{\partial F(y)}{\partial y} & \frac{\partial F(y)}{\partial z} \\
\frac{\partial F(z)}{\partial x} & \frac{\partial F(z)}{\partial y} & \frac{\partial F(z)}{\partial z}
\end{array}\right], } \\
\operatorname{det} J= & J_{11}\left(J_{22} J_{33}-J_{23} J_{32}\right)+J_{12}\left(J_{23} J_{31}-J_{21} J_{33}\right) \\
& +J_{13}\left(J_{21} J_{32}-J_{22} J_{31}\right), \\
\operatorname{tr} J= & J_{11}+J_{22}+J_{33} .
\end{aligned}
$$

From the above Jacobian matrix, we can obtain the matrix determinant $\operatorname{det} J$ and the trace of the matrix $\operatorname{tr} J$ which corresponds to the upper equilibrium point, as shown in Table 3. According to the results in the table, the evolutionary equilibrium state between the CEO, compensation committee, and audit committee is affected by many factors. It is also impossible to determine whether there is a balanced stable point of the three-party game in the above equilibrium points, so it can be combined with the computer simulation.

\section{System Simulation Analysis}

From the above evolutionary game equilibrium analysis, the CEO, compensation committee, and audit committee are also in the process of dynamic game learning, which is constantly learning the information acquisition and adjustment strategy and ultimately achieving evolutionary equilibrium by changing their own strategies and efforts. In order to observe the behaviour trajectory more intuitively, the dynamic game of participant strategy selection is simulated and analysed using MATLAB software. Initially, it is assumed that the CEO, compensation committee, and audit committee have different probabilities of 50\%. Furthermore, in order to reflect the evolution of the system more accurately, the time step is set to 0.04 . The relevant parameters in the three-party game payment matrix are set as follows:

$$
\begin{aligned}
x_{0} & =y_{0}=z_{0}=0.5, \\
m_{1} & =3, \\
m_{2} & =2, \\
a_{1} & =1.5, \\
a_{2} & =1, \\
v_{1} & =10, \\
v_{2} & =5, \\
\beta & =0.5 .
\end{aligned}
$$

5.1. Dynamic Evolution of the CEO's Strategy. In a system, the actions of any party are affected by other parties. In order to analyse the influences of the two special committees on the self-interested behaviour of the CEO, we examine the impact of the different strategy combinations of the compensation committee and audit committee on the evolutionary 


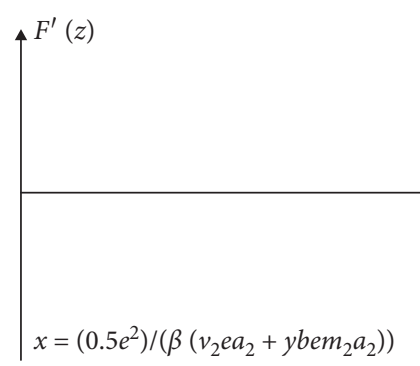

(a)

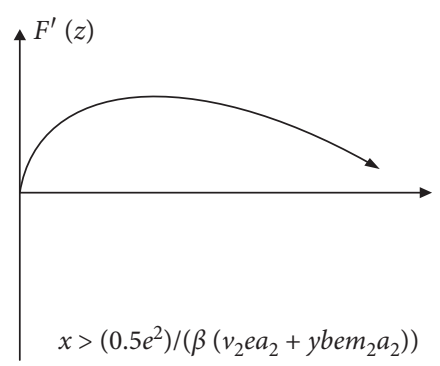

(b)

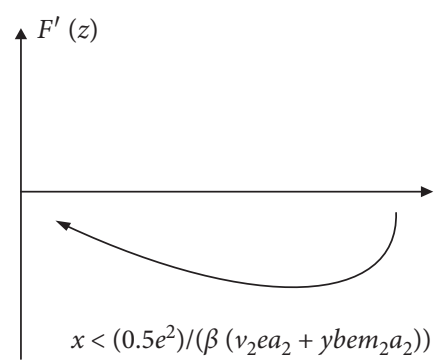

(c)

FIGURE 4: Audit committee's replicator dynamics phase charts.

trajectory of the CEO's behaviour and establish its stable equilibrium point. This is shown in Figures 5 and 6 .

Figure 5 shows the dynamic evolutionary paths of the $\mathrm{CEO}$ in the context of different incentive strategies adopted by the compensation committee. When the incentive coefficient of the compensation committee is small, the CEO tends not to engage in self-interested behaviour, as selfinterested behaviour requires higher costs, while the compensation committee adopts a less incentive. Furthermore, the smaller the incentive coefficient in the compensation committee is, the faster the CEO tends not to engage in selfinterested behaviour. In contrast, when the incentive coefficient of the compensation committee is large, the CEO tends to adopt self-interested behaviour. Therefore, it can be observed that the incentive strength of the compensation committee effectively promotes the motivation of the CEO to conduct self-interested behaviour. Therefore, the compensation committee should adopt the optimal incentive contract in order to motivate the CEO.

Figure 6 shows the dynamic evolutionary paths of the CEO in the context of different supervision strategies which are adopted by the audit committee. It can be observed that the supervision of the audit committee has a restrictive effect on the CEO's self-interested behaviour. When the supervision is small, for the CEO, the supervision threat of the audit committee is not credible, or the negative effect of its supervision is far lower than the benefits which are brought by the compensation committee incentives, so the CEO tends to conduct self-interested behaviour. It is a steady state, and the smaller the supervision strength is, the faster the CEO tends to choose self-interested behaviour. Otherwise, when the CEO observes that the audit committee has supervised behaviour and the intensity is strong, they are more inclined not to choose self-interested behaviour. The greater the intensity of supervision is, the sooner the CEO tends not to engage in self-interested behaviour. At this time, the supervision of the audit committee constitutes a substantial threat, and the self-interested behaviour will suffer more losses.

By comparison, it is discovered that the strategies of the compensation committee and audit committee have the opposite effect on the CEO's behaviour choice. This also explains that when giving the CEO a large salary incentive coefficient to stimulate greater economic output, greater supervision and cooperation from the audit committee are required in order to restrict the CEO's self-interested behaviour while stimulating productive activities. Therefore, the special committees under the board of directors should balance incentive and supervision.

5.2. Dynamic Evolution of the Compensation Committee's Strategy. Figure 7 shows the dynamic evolutionary paths of the compensation committee in the context of different selfinterested behaviour adopted by the CEO. With an increase in the CEO's self-interested behaviour, the compensation committee tends to choose a nonincentive strategy. It can be noted that the occurrence of the CEO's self-interested behaviour inhibits the formulation of the incentive plan of the compensation committee. As observed self-interested behaviour increases, the compensation committee will choose nonincentives in order to curb the CEO's self-interested behaviour. In particular, when the CEO does not conduct self-interested behaviour, then the compensation committee still chooses not to adopt the incentive strategy, demonstrating the inaction of the compensation committee. There are two main reasons which explain this phenomenon. Firstly, the initial probability that the CEO will engage in self-interested behaviour is set as 0.5 , and the compensation committee is more willing to choose nonincentive contract to avoid potential losses. Secondly, the compensation committee did not supervise the CEO, so it could not accurately obtain the information about the CEO's self-interested behaviour.

Figure 8 shows the dynamic evolutionary paths of the compensation committee in the context of different supervision which is adopted by the audit committee. This indicates that when the supervision of the audit committee is at a low level, the compensation committee has reason to believe that the CEO is more likely to conduct self-interested behaviour (Figure 6). As the supervision of the audit committee reduces, the compensation committee is more inclined to choose a nonincentive strategy. However, when supervision reaches a certain level, the compensation committee has reason to believe that the audit committee can effectively restrain the self-interested behaviour of the CEO. When the possibility of the CEO making self-interested behaviour is small, the compensation committee tends to choose incentive strategy, and as supervision increases, the compensation committee will be more inclined to choose incentives. 


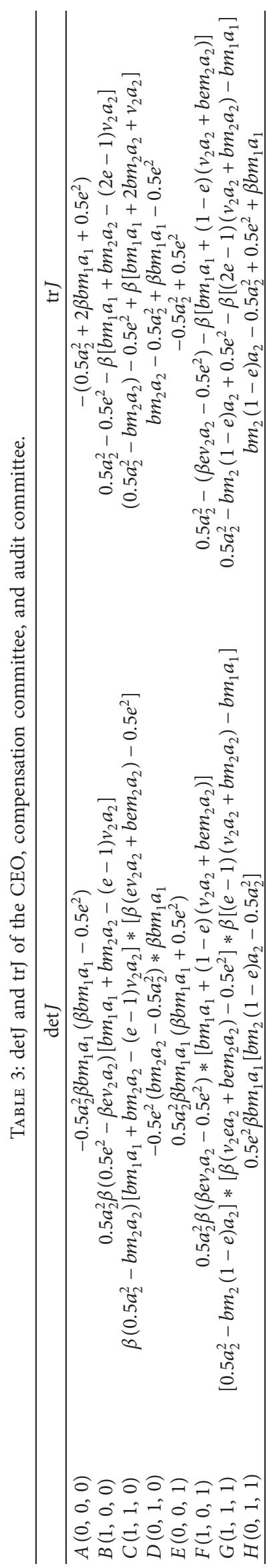




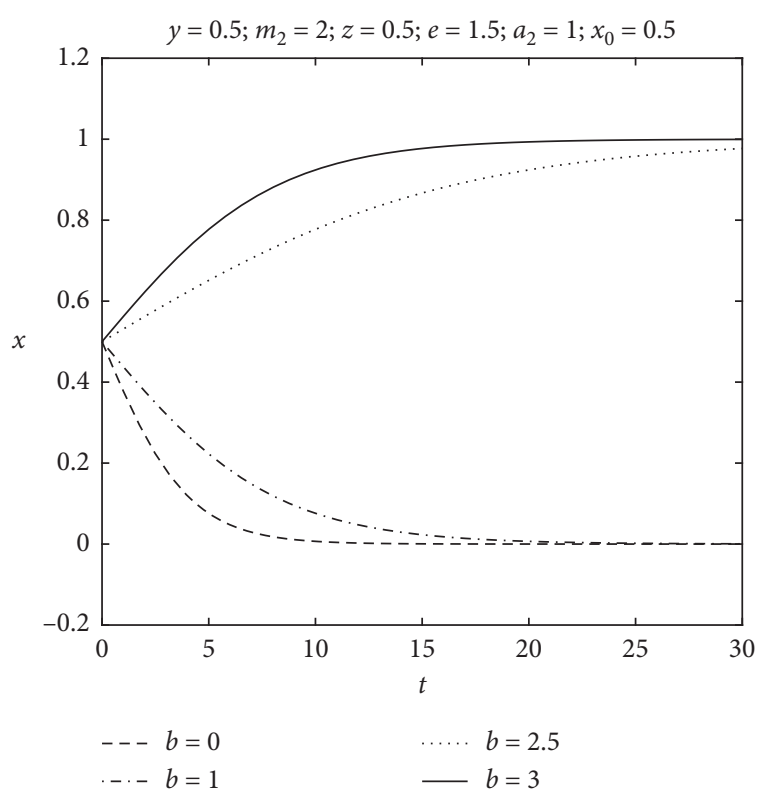

FIgURE 5: Dynamic evolutionary paths of CEO with $b$.

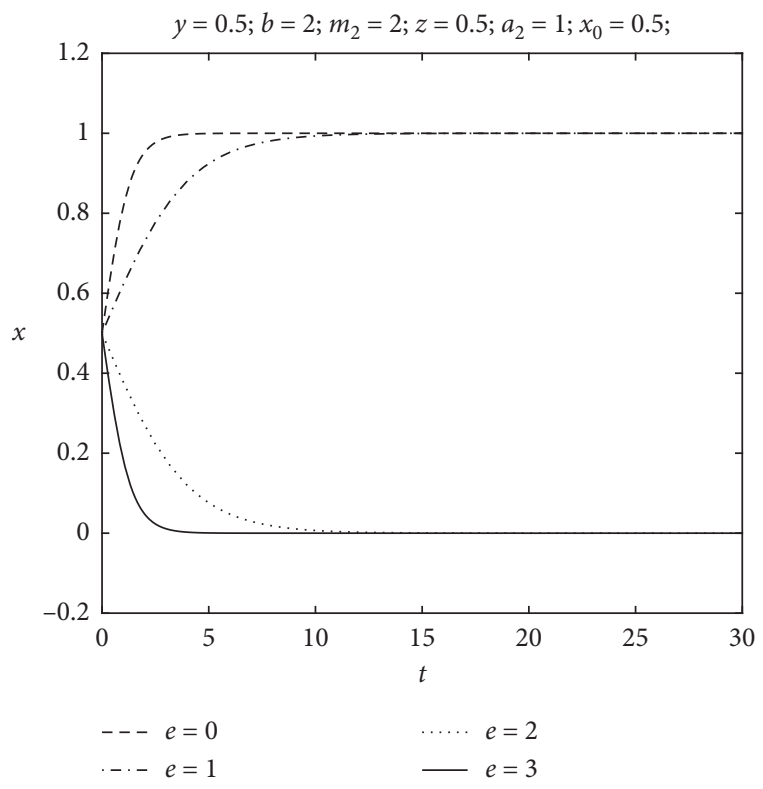

FIGURE 6: Dynamic evolutionary paths of CEO with $e$.

5.3. Dynamic Evolution of the Audit Committee's Strategy. Figure 9 shows the dynamic evolutionary paths of the audit committee in the context of different self-interested behaviour which is adopted by the CEO. This indicates that when the CEO's self-interested behaviour is at a lower level, the audit committee is more inclined to choose an unsupervised strategy due to the cost of supervision. The strategy allows a certain degree of self-interested CEO to exist as a disguised incentive, and the CEO with a certain degree of self-interested behaviour can coordinate the interests of the company and the private interests of managers. This may play a positive role in the performance of the company. In

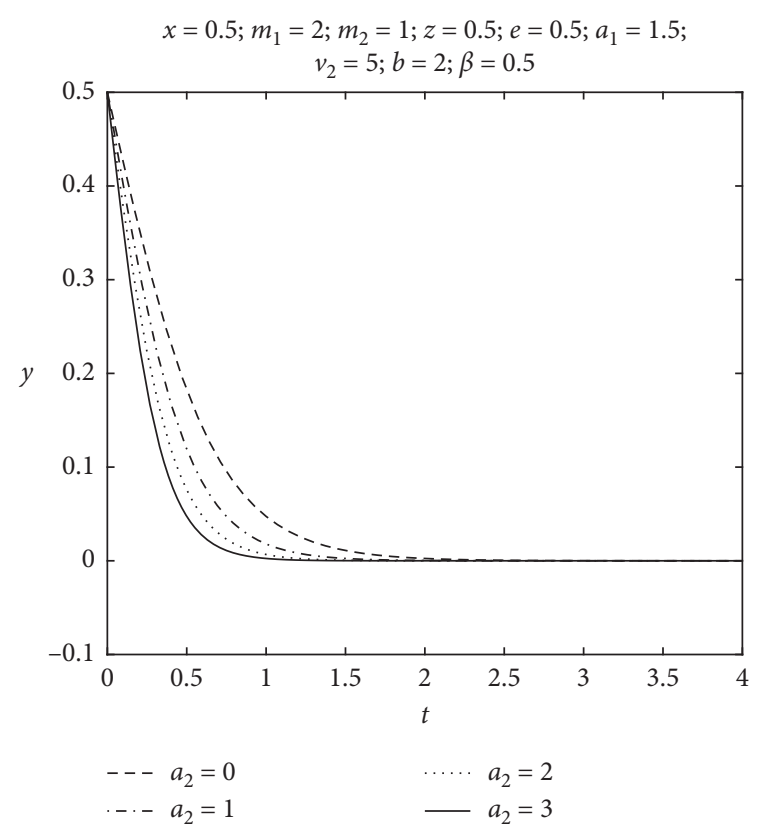

FIGURE 7: Dynamic evolutionary paths of comp with $a_{2}$.

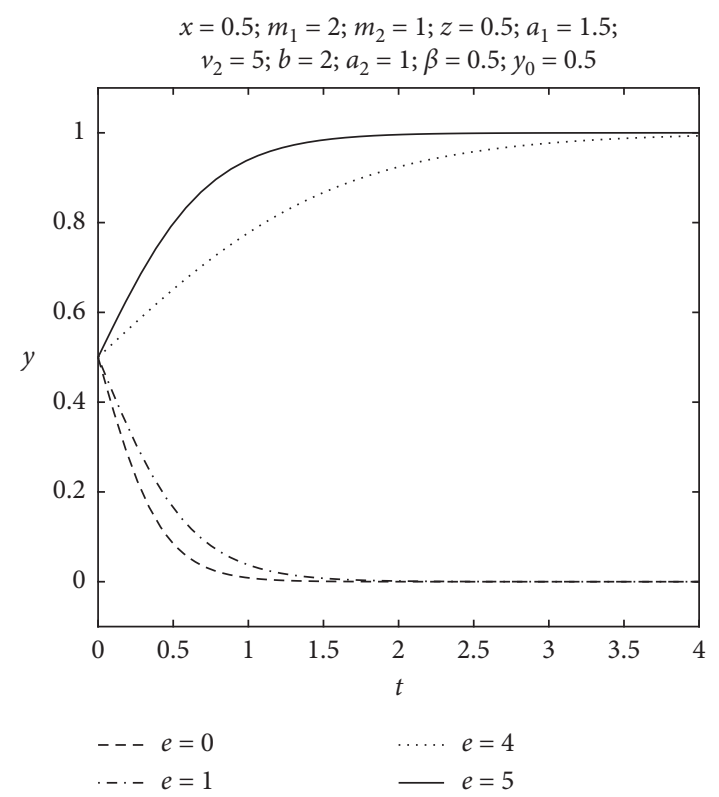

Figure 8: Dynamic evolutionary paths of comp with $e$.

particular, the lower the degree of self-interested behaviour of the CEO, the sooner the audit committee tends not to monitor the strategy. However, when the CEO's self-interested behaviour reaches a certain level, the audit committee is more inclined to choose supervision. If the audit committee finds that the CEO's self-interested behaviour is high, it determines that the CEO's self-interested behaviour already poses a great threat to shareholder interests. At this time, the audit committee will choose to supervise, and as the self-interested behaviour increases, the audit committee will tend to monitor this stabilisation strategy more quickly, in order to reduce the CEO's self-interested behaviour. 


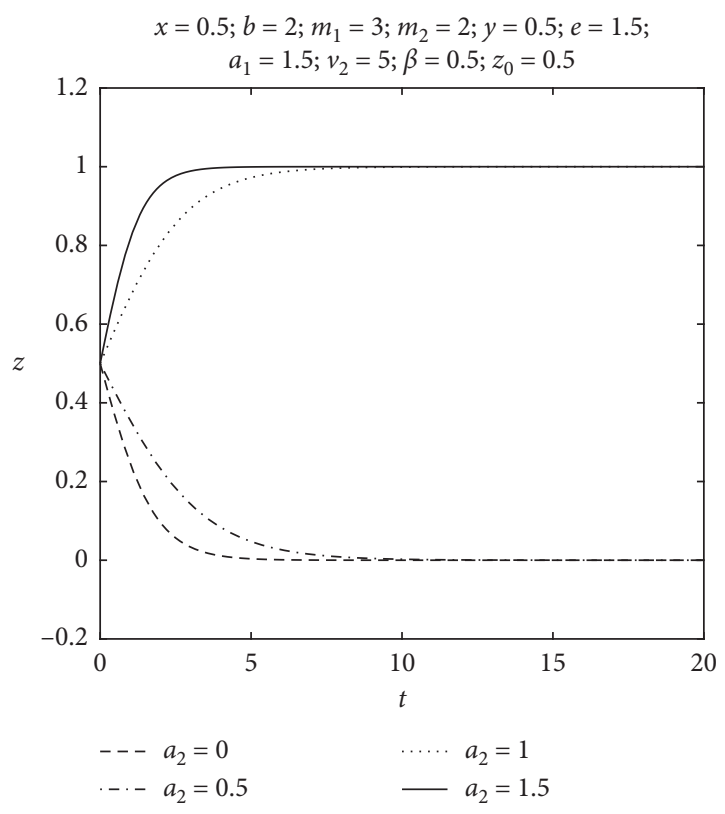

FIGURE 9: Dynamic evolutionary paths of audit with $a_{2}$.

Figure 10 shows the dynamic evolutionary paths of the audit committee in the context of different incentive strategies which are adopted by the compensation committee. When the salary plan developed by the compensation committee is at a lower level, the audit committee chooses not to supervise. There is a reason to believe that when the incentive coefficient is small, the CEO prefers to choose not self-interested behaviour as a stable strategy. As the benefits of adopting not self-interested behaviour are lower than the cost of self-interested behaviour, a rational CEO will choose a lower degree of self-interested behaviour. And with the reduction of incentives of the compensation committee, the audit committee will be more inclined to choose an unsupervised stabilisation strategy. However, when the incentive strength of the compensation committee reaches a particular level, the CEO will have greater incentive to choose selfinterested behaviour in order to seek private income. As a spokesperson for the interests of shareholders, the audit committee will choose to supervise in order to protect shareholder interest from infringement and thereby inhibit the CEO from choosing self-interested behaviour. In particular, with the increase of the incentive strength of the compensation committee, the audit committee will choose to prefer to supervise faster.

5.4. Dynamic Evolution of Tripartite Pure Strategy. It is further considered that there are eight kinds of pure strategy choice, and the change of the microstrategy of one party's game subject can change the choice of other subject strategies. When the participating entities in the system adopt pure strategy, the three parties have two strategic choices; that is to say, there are eight strategic combinations. Through simulation analysis of these eight strategies, when each participant adopts a pure strategy, no party in the subsequent dynamic game is willing to change its original strategy,

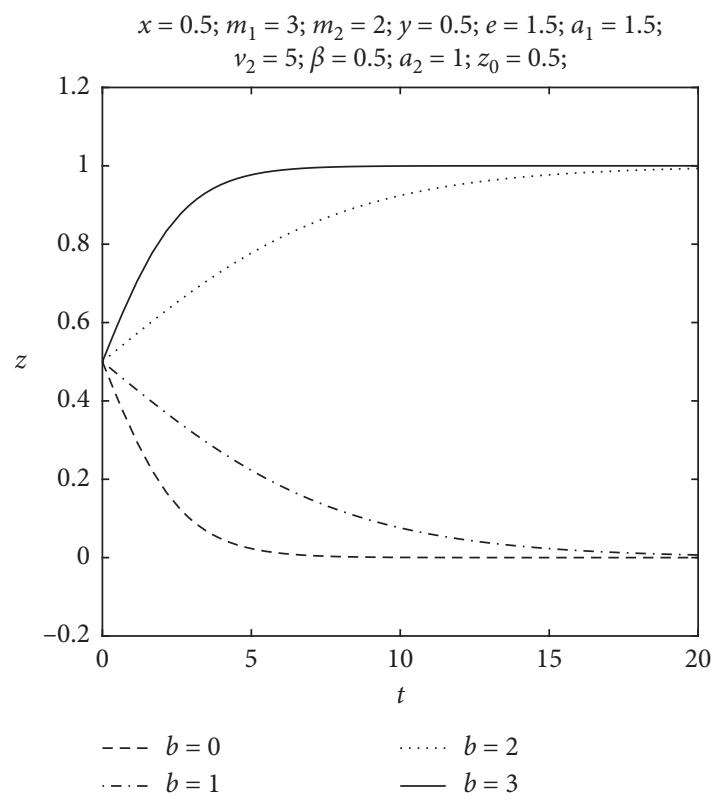

Figure 10: Dynamic evolutionary paths of audit with $b$.

and the alliance evolution result will be stable in equilibrium. However, this state is not relatively stable for system evolution. As long as one party in the system makes minor strategy adjustments, the equilibrium state of system evolution will be broken. Taking strategy $D(0,1,0)$ as an example, Figure 11 shows that the CEO, compensation committee, and audit committee are not willing to adjust their strategies in order to change the existing equilibrium state of the alliance.

When the compensation committee and audit committee keep their initial strategies unchanged, the CEO observes that the compensation committee chooses the incentive strategy, and the audit committee does not supervise; in order to obtain more private benefits, the CEO will adjust their strategy with a small probability $(x=0.01)$. The system equilibrium strategy will then quickly evolve from $D(0,1,0)$ to $C(1,1,0)$, and its evolution process is shown in Figure 12. This shows that when the compensation committee creates a higher salary incentive contract in order to motivate the CEO to provide greater economic output, if the audit committee does not perform its supervisory duties, then the CEO will have great motivation to choose selfinterested behaviour after obtaining this information.

As the spokesperson for the shareholders, the audit committee takes an active governance role. When the compensation committee maintains its initial strategy, the $\mathrm{CEO}$ and the audit committee will adjust their strategies with a small probability $(x=0.01$ and $z=0.01)$. We will then find that the system does not have a stable equilibrium point, and the evolution process is shown in Figure 13. Firstly, the CEO observes that the compensation committee adopts an incentive plan, and the audit committee does not take supervision, then the CEO changes their strategy and chooses self-interested behaviour. Next, when the audit committee observes that the $\mathrm{CEO}$ has self-interested behaviour, it chooses the supervision strategy. Then, the CEO will notice 


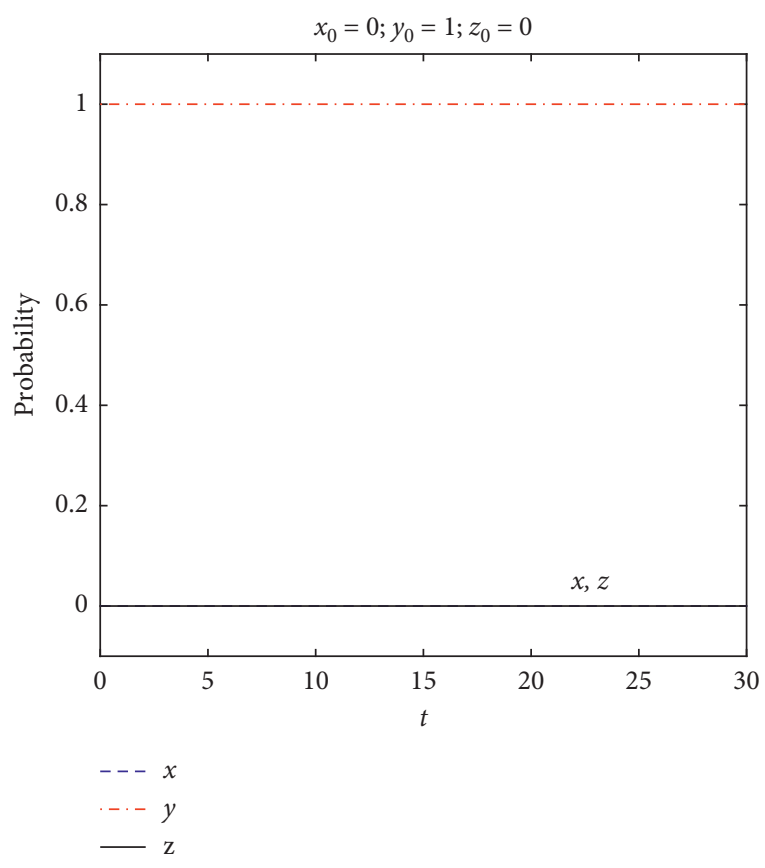

FIGURE 11: Dynamic evolution begins with $D(0,1,0)$.

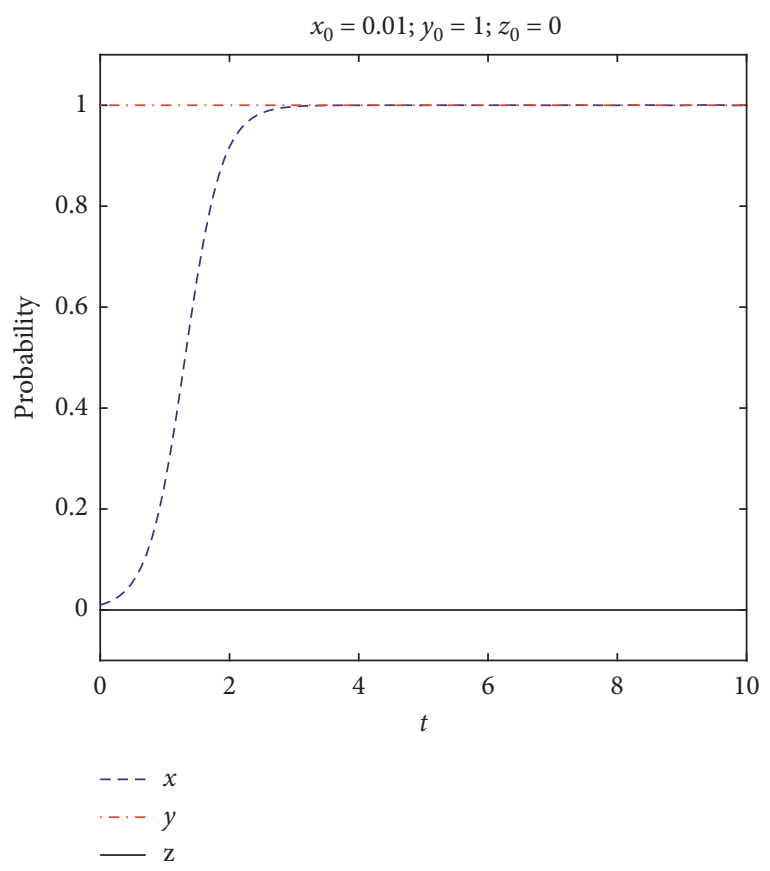

FIgURe 12: Dynamic evolution begins with $(x=0.01)$.

the supervision of the audit committee and choose not to engage in self-interested behaviour to avoid the loss and will remain silent as the optimal strategy for a long time. Finally, after observing that the CEO does not have self-interested behaviour, the audit committee may choose not to supervise and return to the original starting point in order to reduce the cost of supervision. The evolution path is shown in Figure 14. When the compensation committee chooses the

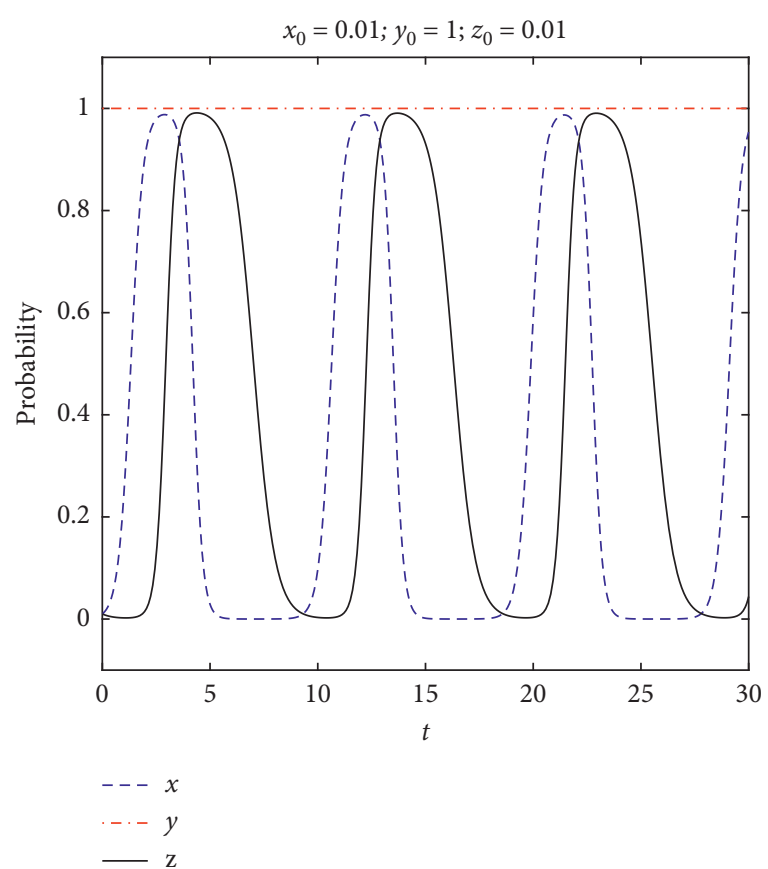

FIgURE 13: Dynamic evolution begins with $x=0.01$ and $z=0.01$.

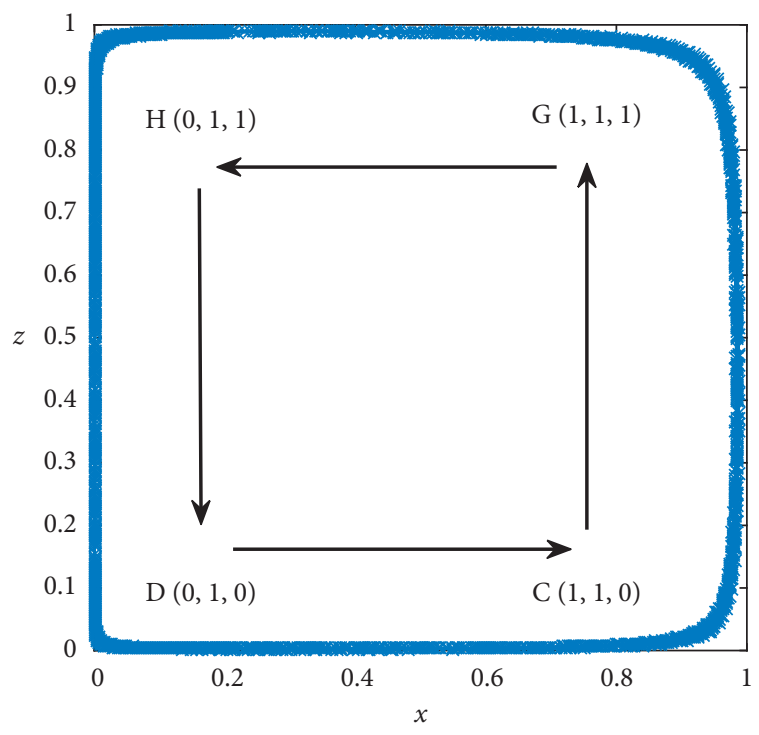

Figure 14: Evolution route of CEO and the audit.

incentive policy, the evolution path of the two is $D(0,1,0)$ $C(1,1,0)-G(1,1,1)-H(0,1,1)-D(0,1,0)$, repeated game.

Considering the existence of the free-rider phenomenon, the compensation committee does not need to bear the cost of supervision, which can lead to the failure of the compensation committee in conducting effective governance, as shown in Figures 12 and 13. Therefore, it is necessary to further explore how the compensation committee can influence the strategic choices of the three parties when adopting a positive governance strategy. Figure 15 shows that, in the absence of audit committee oversight, the compensation committee confirms that the CEO has a 


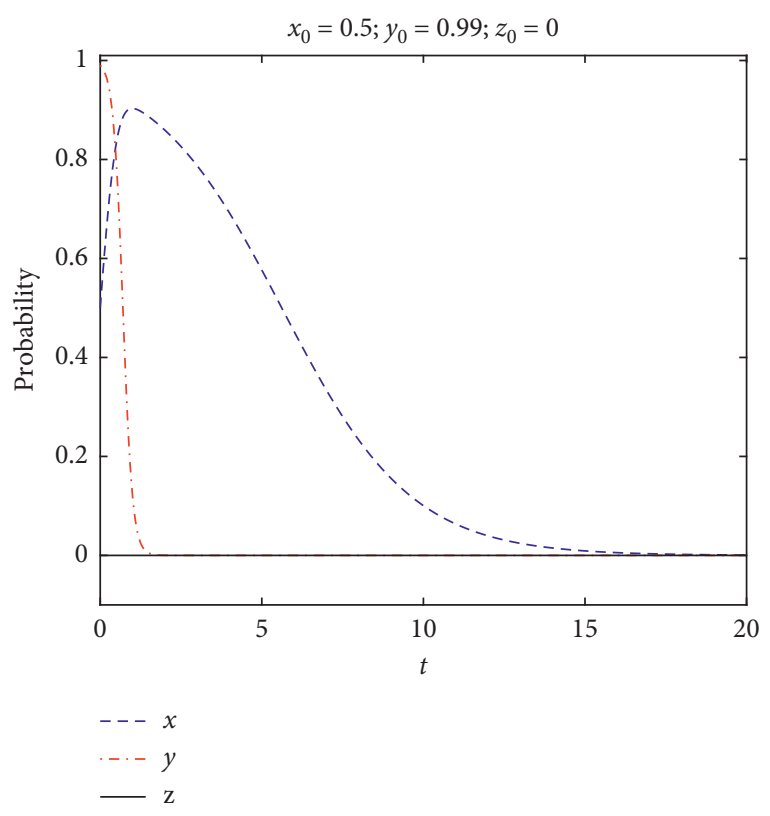

Figure 15: Dynamic evolution begins with $(y=0.99)$.

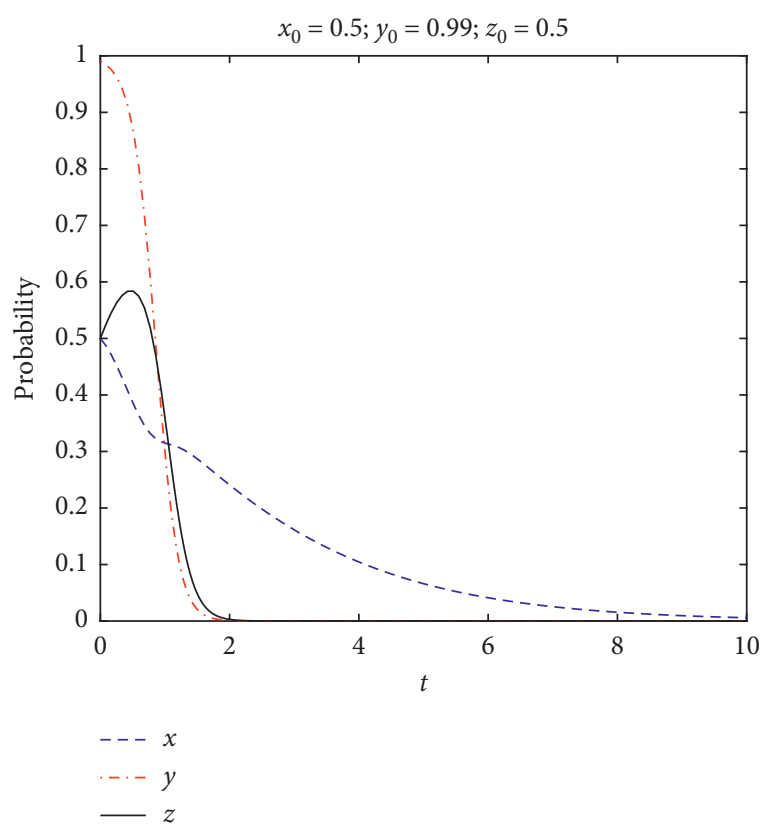

Figure 16: Dynamic evolution begins with $(z=0.5)$.

greater likelihood of self-interested behaviour $(x=0.5)$, and the compensation committee will act as an active manager and choose to make minor strategic adjustments. The compensation committee will soon choose not to incentivise the CEO as a stable strategy, and this can restrain the CEO's self-interested behaviour very well. The CEO's evolutionary trajectory presents an inverted U-shape, and when there is no incentive, the final stability strategy is $A(0,0,0)$. If both the compensation committee and audit committee choose positive governance intervention, assuming the initial strategy is $x=0.5, y=0.99$, and $z=0.5$, the CEO gradually tends not to be self-interested. The evolution path is shown in Figure 16 and this evolves faster than in Figure 15. In suppressing the self-interested behaviour of the CEO, it is necessary to give full play to the dual governance role of the special committees, not only in playing the supervisory function of the audit committee but also in participating in the governance of the compensation committee.

\section{Conclusions and Implications}

The incentive and supervision of CEOs have become key links in resolving agent conflicts and coordinating the interests of owners and managers. Considering the self-interested behaviour of CEO and the dynamic variability of the actor's strategy formulation, we used evolutionary game method to construct the strategic choices for the CEO, compensation committee, and audit committee. Furthermore, we analysed the incentive and supervision issues from the internal perspective of the special committees and explored the evolution path trajectory and factors which affect the stability strategy. We reached the following conclusions. Firstly, we established that there is no stable equilibrium point in the system and one of the strategic choices is influenced by the other two parties and that the special committee plays an important role in incentive and supervision. Secondly, due to the existence of the free-rider problem, there may be excessive incentives in the compensation committee. In order to motivate the CEO to create a greater economic output, the compensation committee will choose a more incentivised strategy. If the audit committee adopts a strategy of inaction, it will encourage the CEO's self-interested behaviour. Thirdly, there is a balance between the special committees and the CEO. The initial willingness and intensity of the participants will influence the strategic choices of all three parties. From the perspective of governance effect, the CEO's strategy choice is influenced by the special committees, and passively undertakes incentive and supervision. In order to achieve a better governance effect, the compensation committee and audit committee must coordinate in order to achieve a positive governance strategy.

Based on the above research conclusions, the following countermeasures are proposed. Firstly, the functions of the special committees of the board of directors must be strengthened. The functions of the special committees of the board of directors at many listed companies in China are quite limited. Due to unclear responsibilities, many members of the special committee did not understand the specific goals and showed inaction. Secondly, a collaborative operation system of special committees should be established. The compensation committee and audit committee should share the cost of supervision and realise the coordination mechanism between the two entities. Through information and cost sharing, excessive incentive issues caused due to a lack of information and inadequate supervision can be avoided, so as to improve the internal governance of the board. Finally, the incentive mechanism requires improvement. Due to inconsistency between the principal and the agent, the problem of agency conflict leads to the CEO's 
self-interested behaviour. Therefore, it is necessary to explore and improve the long-term incentive plan, while at the same time, establishing corresponding mechanisms in order to avoid motivating the CEO's self-interested behaviour.

Our study had some limitations. In this study, we stressed the importance of the special committee and only used financial measures in order to judge the strategic choices of the CEO and special committees. In fact, we must fully consider the combination of financial and nonfinancial performance measures when designing executive compensation contracts [27, 28]. Furthermore, China famously operates under a dual-class structure. We only focused on the effectiveness of special committee governance. Owners or the government may have more supervisory powers, and we must consider the role of government supervision in future studies. In addition, Abbasi et al. [29] and Zalata et al. [30] state that female directors on audit committees are expected to oversee management effectively and thereby improve audit quality because female directors are more likely to have lower tolerance towards opportunistic behaviour. Therefore, some characteristics of subjects, such as age, tenure, or gender, may influence their strategy choice, and we will add these personal characteristics to future studies.

\section{Data Availability}

The data used to support the findings of this study are included within the article and are available upon citations.

\section{Conflicts of Interest}

The authors declare that there are no conflicts of interest regarding the publication of this paper.

\section{Acknowledgments}

This research was funded by the Natural Science Foundation of Shandong Province, under Grant no. ZR2019QG005.

\section{References}

[1] R. Kalelkar, "Effect of audit and compensation committee membership overlap on audit fees," Asian Review of Accounting, vol. 25, no. 1, pp. 34-57, 2017.

[2] P. Collier and A. Gregory, "Audit committee effectiveness and the audit fee," European Accounting Review, vol. 5, no. 2, pp. 177-198, 1996.

[3] N. Sultana, J.-L. W. Mitchell Van der Zahn, and S. Cahan, "Earnings conservatism and audit committee financial expertise," Accounting \& Finance, vol. 55, no. 1, pp. 279-310, 2015.

[4] U. Bajra and S. Čadež, "Audit committees and financial reporting quality: the 8th EU company law directive perspective," Economic Systems, vol. 42, no. 1, pp. 151-163, 2018.

[5] C. Ghafran and N. O'Sullivan, "The impact of audit committee expertise on audit quality: evidence from UK audit fees," The British Accounting Review, vol. 49, no. 6, pp. 578-593, 2017.

[6] U. Hoitash and R. Hoitash, "Conflicting objectives within the board: evidence from overlapping audit and compensation committee members," Group Decision and Negotiation, vol. 18, no. 1, pp. 57-73, 2009.

[7] M. Bugeja, Z. Matolcsy, and H. Spiropoulos, "The association between gender-diverse compensation committees and CEO compensation," Journal of Business Ethics, vol. 139, no. 2, pp. 375-390, 2016.

[8] M. A. Abernethy, Y. F. Kuang, and B. Qin, "The influence of CEO power on compensation contract design," The Accounting Review, vol. 90, no. 4, pp. 1265-1306, 2015.

[9] S. Kanapathippillai, F. Gul, D. Mihret, and M. B. Muttakin, "Compensation committees, CEO pay and firm performance," Pacific-Basin Finance Journal, vol. 57, Article ID 101187, 2019.

[10] C. Laux and V. Laux, "Board committees, CEO compensation, and earnings management," The Accounting Review, vol. 84, no. 3, pp. 869-891, 2009.

[11] D. J. Cooper, C. A. Ioannou, and S. Qi, "Endogenous incentive contracts and efficient coordination," Games and Economic Behavior, vol. 112, pp. 78-97, 2018.

[12] C.-K. Yu, M. van der Schaar, and A. H. Sayed, "Informationsharing over adaptive networks with self-interested agents," IEEE Transactions on Signal and Information Processing Over Networks, vol. 1, no. 1, pp. 2-19, 2015.

[13] M. C. Jensen and W. H. Meckling, "Theory of the firm: managerial behavior, agency costs and ownership structure," Journal of Financial Economics, vol. 3, no. 4, pp. 305-360, 1976.

[14] F. Focke, E. Maug, and A. Niessenruenzi, "The impact of firm prestige on executive compensation," Journal of Financial Economics, vol. 123, no. 2, pp. 313-336, 2016.

[15] J. Lee and J. Park, "The impact of audit committee financial expertise on management discussion and analysis (MD\&A) tone," European Accounting Review, vol. 28, no. 1, pp. 129-150, 2018.

[16] C. L. Schrader and H.-L. Sun, "How does the type of equity compensation of audit committee affect audit fees?" Advances in Accounting, vol. 45, Article ID 100411, 2019.

[17] E. Alvi, "Fairness and self-interest: an assessment," The Journal of Socio-Economics, vol. 27, no. 2, pp. 245-261, 1998.

[18] M. Markus, E. Kals, and M. Jürgen, "Fairness, self-interest, and cooperation in a real-life conflict," Journal of Applied Social Psychology, vol. 38, no. 3, pp. 684-704, 2008.

[19] A. L. Boone and J. H. Mulherin, "Who monitors the monitor? The use of special committees by target firms in corporate takeovers," Journal of Corporate Finance, vol. 44, pp. 388-404, 2017.

[20] L. A. Bebchuk, J. M. Fried, and D. I. Walker, "Managerial power and rent extraction in the design of executive compensation," The University of Chicago Law Review, vol. 69, no. 3, pp. 751-846, 2002.

[21] J. Core and D. F. Larcker, "Performance consequences of mandatory increases in executive stock ownership," Journal of Financial Economics, vol. 64, no. 3, pp. 317-340, 2002.

[22] M. T. Kartal, C. İbiş, and Ö. Çatıkkaş, "Adequacy of audit committees: a study of deposit banks in Turkey," Borsa Istanbul Review, vol. 18, no. 2, pp. 150-165, 2018.

[23] L. Chourou, E. Abaoub, and S. Saadi, "The economic determinants of CEO stock option compensation," Journal of Multinational Financial Management, vol. 18, no. 1, pp. 61-77, 2008.

[24] L. Kao and A. Chen, "How a pre-IPO audit committee improves IPO pricing efficiency in an economy with little value uncertainty and information asymmetry," Journal of Banking \& Finance, vol. 110, Article ID 105688, 2019. 
[25] S. Balsam, J. Boone, H. Liu, and J. Yin, "The impact of say-onpay on executive compensation," Journal of Accounting and Public Policy, vol. 35, no. 2, pp. 162-191, 2016.

[26] D. Friedman, "On economic applications of evolutionary game theory," Journal of Evolutionary Economics, vol. 8, no. 1, pp. 15-43, 1998.

[27] M. Cho, S. Ibrahim, and Y. Yan, "The use of nonfinancial performance measures in CEO bonus compensation," Corporate Governance: An International Review, vol. 27, no. 4, pp. 301-316, 2019.

[28] H. Aldamen, J. Hollindale, and J. L. Ziegelmayer, "Female audit committee members and their influence on audit fees," Accounting \& Finance, vol. 58, no. 1, pp. 57-89, 2018.

[29] K. Abbasi, A. Alam, and M. B. U. Bhuiyan, "Audit committees, female directors and the types of female and male financial experts: further evidence," Journal of Business Research, vol. 114, pp. 186-197, 2020.

[30] A. M. Zalata, V. Tauringana, and I. Tingbani, "Audit committee financial expertise, gender, and earnings management: does gender of the financial expert matter?" International Review of Financial Analysis, vol. 55, pp. 170-183, 2018. 